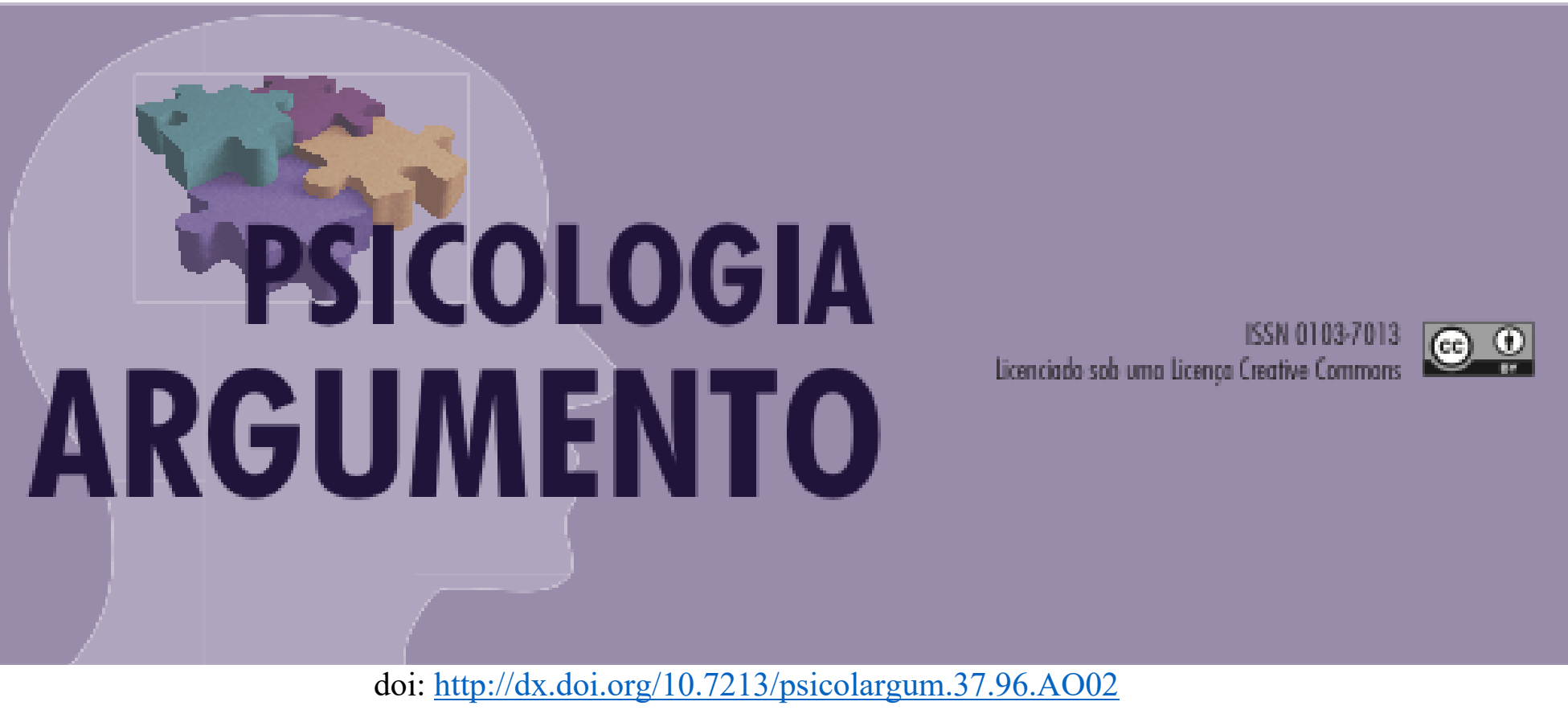

\title{
A formação acadêmica para a integração da religiosidade/espiritualidade na prática do psicólogo
}

The academic formation for the integration of religiosity and spirituality in the psychologist's practice

La formación académica para la integración de la religiosidad/ espiritualidad en la práctica del psicólogo

Larissa Priscila de Oliveira

ORCID: http://orcid.org/0000-0001-9394-020X

Residente em Psicologia da Universidade de São Paulo, email: larissa.priscila@hotmail.com.

Gabriele Serur

ORCID: http://orcid.org/0000-0002-8835-9792

Bolsista de Iniciação Científica da Pontifícia Universidade Católica do Paraná, email: gabriele.serur@hotmail.com.

Renate Brigitte Michel

ORCID: http://orcid.org/0000-0002-7094-1899

Psicóloga e Doutora em Teologia da Pontifícia Universidade Católica do Paraná, email: michelbrenate@gmail.com.

Mary Rute Gomes Esperandio

ORCID: http://orcid.org/0000-0001-8521-8794

Professora adjunta do Programa de Pós-gradução em Teologia da Pontifícia Universidade

Católica do Paraná, email: mresperandio@gmail.com. 


\section{Resumo}

Várias pesquisas apontam que os profissionais de saúde, destacando-se entre eles os/as psicólogos/as, costumam negligenciar a escuta dos aspectos espirituais e religiosos, evitando o tema e no máximo encaminhando o paciente para o serviço da pastoral, quando este é existente. Por intermédio da identificação dos cursos de Psicologia nas diversas instituições da região Sul e Sudeste, efetuou-se uma pesquisa documental. A partir da análise das grades curriculares disponíveis on-line, buscou-se encontrar disciplinas cujo nome sugerisse a abordagem do tema da espiritualidade/religiosidade. Identificou-se que a integração dos aspectos religiosos/espirituais com a prática profissional foi encontrada em apenas 4 (quatro) descrições disciplinares. Este dado comprova o silêncio que reina sobre este tema na formação do profissional psicólogo, bem como a falta de diálogo entre a Psicologia e a Teologia, mesmo nas escolas confessionais. É imperativo que se reveja a postura dos centros de formação, incluindose tanto a presença do tema na grade curricular como fomentando a pesquisa interdisciplinar. Palavras-chave: espiritualidade/religiosidade; capacitação profissional; Teologia.

Abstract
Several studies indicate that health professionals, especially psychologists, tend to neglect listening to spiritual and religious aspects, avoiding the topic and, at best, referring the patient to pastoral service when it exists. Through the identification of Psychology courses in the various institutions of the South and Southeast, a documentary research was carried out. From the analysis of curricula available online, we sought to find disciplines whose name suggested approaching the theme of spirituality/ religiosity. It was found that the integration of religious/ spiritual aspects with professional practice was found in only four subjects. This data proves the silence that reigns on this theme in the formation of the professional psychologist, as well as the lack of dialogue between Psychology and Theology, even in confessional schools. It is imperative to review the posture of training centers, including both the presence of the theme in the curriculum and fostering interdisciplinary research.

Keywords: Spirituality; Professional training; Theology.

\section{Resumen}

Varios estudios indican que los profesionales de la salud, especialmente los psicólogos, tienden a dejar de escuchar los aspectos espirituales y religiosos, evitando el problema y, a lo sumo, remitiendo al paciente al servicio pastoral cuando existe. A través de la identificación de cursos de psicología en las diversas instituciones del sur y sudeste, se realizó una investigación documental. A partir del análisis de los planes de estudio disponibles en línea, buscamos encontrar disciplinas cuyo nombre sugiriera abordar el tema de la espiritualidad / religiosidad. Se encontró que la integración de los aspectos religiosos / espirituales con la práctica profesional se encontró en solo 4 (cuatro) descripciones disciplinarias. Estos datos demuestran el silencio que reina sobre este tema en la formación del psicólogo profesional, así como la falta de diálogo entre psicología y teología, incluso en las escuelas confesionales. Es imprescindible revisar la postura de los centros de capacitación, incluida la presencia del tema en el plan de estudios y fomentar la investigación interdisciplinaria.

Palabras clave: espiritualidad / religiosidad; capacitación profesional; Teología

\section{Introdução}

A escuta atenta aos pacientes internados em hospitais ou em tratamento de saúde em clínicas especializadas não deixa dúvidas a respeito da importância dos aspectos 
espirituais e religiosos $(\mathrm{E} / \mathrm{R})$ para esta clientela, aspectos esses extremamente importantes tanto nas questões de busca de significado como nas estratégias de enfrentamento (Elias \& Giglio, 2001; Geronasso \& Coelho, 2012; Gobato \& Araújo, 2010; Hefti, 2011; Junior, 2011; Koenig, 2012; Teixeira \& Lefèvre, 2003). No entanto, várias pesquisas apontam que os profissionais de saúde, destacando-se entre eles os psicólogos, costumam negligenciar esta escuta, evitando o tema e no máximo encaminhando o paciente para o serviço da pastoral, quando este é existente. (Esperandio, 2014; Koenig, 2012; Peres, Simão \& Nasello, 2007).

Em pesquisa de campo, desenvolvida pela autora com alunos do $5^{\circ}$ ano do curso de psicologia, estagiando na área da Psicologia da Saúde/hospitalar, constatou-se que os alunos admitem a importância da $\mathrm{E} / \mathrm{R}$ dos pacientes como estratégia de enfrentamento, no entanto, na prática cotidiana, não integram estes aspectos nos seus atendimentos. Neste sentido, Peres (2004) alerta que o grande desafio da psicoterapia é promover uma mudança de paradigma, incluindo efetivamente a dimensão $E / R$ na sua visão do ser humano como um ser bio-psico-social-espiritual. No entanto, os psicoterapeutas ainda trabalham na perspectiva da racionalização e, portanto, a E/R fica afastada da prática da Psicologia, apesar destes aspectos continuarem a fazer parte da vida dos pacientes.

O presente estudo buscou identificar de que maneira a formação acadêmica está preparando o profissional de Psicologia para intervir em situações cuja demanda envolva a interface dos aspectos psicológicos e da E/R. Inicialmente será apresentada uma breve reflexão sobre o interesse e desafios da Psicologia na abordagem da E/R. Em seguida, serão apresentados os resultados do levantamento nas grades curriculares dos cursos de Psicologia das regiões sul e sudeste, da presença de disciplinas que se refiram ao preparo para o manejo do futuro profissional, das questões relativas à $E / R$ do paciente sob seus cuidados. Por fim estes dados são discutidos, culminando com a sugestão de uma possível proposta de uma disciplina para a instrumentação do estudante de psicologia para o manejo com as questões da $\mathrm{E} / \mathrm{R}$ na sua futura prática profissional.

$\mathrm{O}$ interesse da Psicologia pela E/R não é novo. Ávila (2007) aponta que o nascimento da chamada Psicologia da Religião pode ser reportado à década de 1880 , apesar de que o próprio Wundt, conhecido como pai da Psicologia Experimenta, ter dedicado 3 volumes da sua extensa obra exclusivamente para o estudo da religião e da mitologia, alguns anos antes. Freitas (2015) indica que o primeiro livro intitulado de Psicologia da Religião, de autoria de Diller Starbuck, foi publicado em 1899 mas é W. 
James quem é reconhecido como o principal pioneiro neste tema, tendo publicado em 1902 seu livro As variedades da Experiência Religiosa - um estudo sobre a natureza humana, a qual pode ser considerada como a origem da Psicologia da Religião. "É notável que, quase desde seu nascimento, a psicologia se tenha voltado para o comportamento religioso, ou seja, para o comportamento dirigido para o objeto religioso" (Paiva, 2005, p. 32). Portanto, percebe-se que estes pioneiros acima citados entenderam que a religião podia ou até deveria ser considerada como um objeto propício ao estudo dentro da Psicologia.

No entanto esta efervescência ao final do século XIX e nas duas primeiras décadas do século XX, tiveram um declínio rápido após 1920. Freitas (2015) apud Byrnes (1984) e Beit-Hallahmi (1989), relacionam alguns motivos para a redução ou quase desaparecimento do tema no campo da Psicologia. Dentre eles a autora cita:

O fracasso da psicologia em separar-se da teologia ao investigar os fenômenos religiosos; o seu esforço quase desesperado para ser reconhecida como "científica" num cenário de influências positivistas e iluministas; os conflitos geralmente vividos tanto pelos pesquisadores quanto pelos seus sujeitos quando da investigação do assunto; a subjetividade do fenômeno religioso, que dificulta suas abordagem "empírica" e "objetiva"; a influência do behaviorismo, que reduziu o objeto de estudo da Psicologia ao comportamento observável, e da psicanálise freudiana, que reduziu a religião a uma ilusão da humanidade (Freitas, 2015, p.3).

Estes fatos dominaram o século XX. No entanto, nem todas as abordagens psicológicas, nem todos os representantes destas abordagens, tinham a mesma visão da E/R como fontes de patologia ou questões que impediam a Psicologia de ser científica. Pelo contrário, autores clássicos como Jung, Frankl, Maslow, Allport, Fowler, Grof e Assagioli, entre outros, entendem que a R/E pode ser também um fator de proteção e de enfrentamento para uma vasta gama de conflitos psíquicos, sendo importantes auxiliares na relação com a saúde mental e física (Ávila, 2007).

Apesar desses eminentes representantes da Psicologia, as questões da E/R perderam espaço e reconhecimento no meio acadêmico científico.

As novas categorias "seculares" opõem-se às chamadas categorias "religiosas" do self, cercandoas de suspeitas e desconfianças. Com isso, deslegitima a experiência religiosa - mesmo aquela que é vivida pelas pessoas como sendo de cunho genuinamente espiritual - ao trazer para o âmbito do psíquico tudo aquilo que, a rigor, do ponto de vista epistemológico, deveria ser deixado no âmbito teológico. Por outro lado, as "categorias religiosas" dentro da psicologia, embora não deixem de existir, acabam sendo marginalizadas, consideradas "menores", "não científicas" e epistemologicamente frágeis, porque adentram o universo da teologia (Freitas, 2015, p. 3). 
O que se observa atualmente é que, apesar de perceber algumas aberturas a novos modelos, os quais integram os aspectos $\mathrm{E} / \mathrm{R}$ com os estudos da Psicologia, o que impera é um grande silêncio acerca do tema durante a formação profissional do psicólogo.

\section{Objetivos}

O objetivo geral foi identificar se os estudantes de psicologia têm sido instrumentalizados formalmente durante sua graduação para intervir em situações que envolvam o coping religioso/espiritual em sua prática terapêutica, sendo os objetivos específicos: (1) verificar a disponibilidade de disciplinas relacionadas ao tema da Psicologia e Religiosidade/Espiritualidade nas instituições de ensino superior e suas localizações demográficas; (2) verificar se há relação entre a disponibilidade de disciplinas relacionadas ao tema da Psicologia e Religiosidade/Espiritualidade nas instituições de ensino superior e a categoria administrativa da instituição (se pública ou privada) ou o modo de sua mantença (mantidas pelo Poder Público ou pelo direito privado de maneira comunitária, filantrópica, confessional, etc) e (3) relacionar os resultados encontrados na pesquisa quantitativa com o resultado da pesquisa em literatura atual sobre a preparação do profissional de Psicologia.

\section{Método}

Para fins deste estudo utilizou-se a pesquisa documental, uma vez que ela acessível e pertinente aos objetivos do presente estudo, qual seja, a identificação das disciplinas sobre E/R ofertadas em cursos de Psicologia. A pesquisa documental coincide, em muitos aspectos, com a pesquisa bibliográfica. No entanto, Gil (2002) expõe a diferença entre elas:

\footnotetext{
A diferença essencial entre ambas está na natureza das fontes: enquanto a pesquisa bibliográfica se utiliza fundamentalmente das contribuições dos diversos autores sobre determinado assunto, a pesquisa documental vale-se de materiais que não recebem ainda um tratamento analítico, ou que ainda podem ser reelaborados de acordo com os objetivos da pesquisa. (Gil, 2002, p. 45).
}

$\mathrm{Na}$ primeira fase da pesquisa foi realizada uma busca por todos os Centros Universitários, Universidades e Faculdades dos sete estados pertencentes à Região Sul e Sudeste (Espirito Santo, Minas Gerais, Paraná, Rio de Janeiro, Rio Grande do Sul, Santa Catarina e São Paulo) que ofertavam, durante do ano de 2017, o curso de Psicologia e 
cuja inscrição esteja regularizada junto ao Ministério da Educação (MEC) em sua plataforma virtual, disponibilizada através do endereço http://emec.mec.gov.br/.

A partir da identificação dos cursos de Psicologia nas diversas instituições, efetuou-se, na segunda fase, a análise das grades curriculares, a fim de encontrar disciplinas cujo nome sugerisse a abordagem do tema da E/R. Para tanto, foram consideradas as grades curriculares disponíveis on-line e que estivessem vigorando em turmas abertas, desconsiderando, assim, grades curriculares de turmas já formadas. Para esta análise foram considerados nomes sugestivos os que tinham em sua composição uma ou mais das seguintes palavras-chave: ciências da religião/espiritualidade, coping religioso/espiritual, cultura religiosa, divino, espiritualidade, fé, psicologia da religião e religiosidade, transcendente, transcendência e religião, mantendo-se a abertura para achados que sugerissem a abordagem ao tema proposto, mesmo que com nomes que não incluíssem nenhuma das palavras-chave previamente escolhidas.

Após o levantamento das disciplinas que correspondiam aos critérios de busca, a próxima etapa da pesquisa baseou-se na análise das ementas 1 disciplinares das disciplinas identificadas. Essa terceira fase de investigação foi desdobrada em dois procedimentos: a) em um primeiro momento, através do conteúdo disponibilizado nos sites oficiais das instituições de ensino; b) caso a ementa não estivesse disponível na plataforma virtual, esta foi solicitada ao coordenador do curso de Psicologia da instituição de ensino por email.

\section{Resultados}

Foi possível constatar, na primeira fase da pesquisa que, no momento, o curso de Psicologia é disponibilizado em 118 (cento e dezoito) instituições de ensino da Região Sul e 241 (duzentos e quarenta e um) instituições de ensino da Região Sudeste, totalizando 359 (trezentos e cinquenta e nove) cursos em atividade nas duas regiões. Destas 359 instituições de ensino que ofertam o curso de Psicologia atualmente, 291 instituições disponibilizam, em suas plataformas virtuais oficiais, a grade curricular oferecida pelo curso.

No que se refere à natureza administrativa das instituições de ensino analisadas, constatou-se que 7,9\% dessas sãos públicas, ou seja, são de origem estatal ou governamental. A maioria, portanto, são instituições de ensino de caráter privado, representando $92,1 \%$ da amostra. 
A análise das 291 instituições encontradas permitiu a identificação de 31 disciplinas sugestivas ao tema da E/R em 28 grades curriculares, o que corresponde a 10,6\% das grades curriculares inicialmente encontradas. Os termos "Fenômeno Religioso", "Senso Religioso", "Religiosidade" e "Experiência Religiosa" apareceram como objeto de estudo em 71,4\% (10) descrições disciplinares. Os termos "estudo antropológico", "formação cultural" e "aspectos históricos" das religiões e dos aspectos religiosos/espirituais estiveram presentes em 35,7\% delas (5 disciplinas), demonstrando uma preferência pela abordagem conceitual e isolada dos aspectos religiosos/espirituais.

Quanto ao caráter ideológico das instituições, notou-se um número substancial de instituições cujo funcionamento tem como base princípios religiosos. $42,8 \%$ das instituições analisadas e que disponibilizaram disciplinas sugestivas ao tema de $\mathrm{E} / \mathrm{R}$ pertencem às Faculdade/Universidade confessionais.

As disciplinas reconhecidas pelos seus títulos como sugestivas ao nosso tema foram encontradas em todos os estados, exceto no estado do Espirito Santo. Na Região Sul, foi possível observar o domínio dos estados do Paraná (46\%) e Rio Grande do Sul $(45 \%)$ em relação à Santa Catarina $(9 \%)$ no que se refere à oferta das disciplinas deste tema. Esse dado pode ser justificado pelo número reduzido de instituições de ensino superior em Santa Catarina se comparado aos dois estados vizinhos. Na Região Sudeste o predomínio foi do estado de Minas Gerais (47\%), seguido dos estados do Rio de Janeiro (29\%) e São Paulo (24\%) (Tabela 1). 
Tabela1.

Distribuição das disciplinas por instituições e estados.

\begin{tabular}{|c|c|c|}
\hline Estado & Instituição de Ensino Superior & Disciplinas \\
\hline \multirow{9}{*}{ Minas Gerais } & $\begin{array}{l}1 \text { - Centro Universitário Do Leste De Minas Gerais - } \\
\text { UNILESTEMG }\end{array}$ & Antropologia e Religião \\
\hline & 2 - Centro de Ensino Superior de Juiz de Fora- CES/JF & Antropologia da Religião \\
\hline & 3 - Faculdade Atenas & Psicologia e Religiosidade \\
\hline & $\begin{array}{l}4 \text { - Faculdade de Estudos Administrativos de Minas } \\
\text { Gerais - FEAD MG }\end{array}$ & Ciências da Religião \\
\hline & 5 - Universidade Federal do Triângulo Mineiro - UFTM & Fenomenologia e Espiritualidade \\
\hline & 6 Univercidade Federol de Minge Geraic JFMG & Freud e a religião \\
\hline & o - Uirversidade rederal de inintas Gerals - Urivio & Psicologia e senso religioso \\
\hline & 7 - Universidade Federal de Juiz de Fora - UFJF & Psicologia da Religião \\
\hline & $\begin{array}{l}8 \text { - Pontifícia Universidade Católica de Minas Gerais - } \\
\text { PUC MINAS }\end{array}$ & $\begin{array}{l}\text { Cultura Religiosa: Fenômeno Religioso } \\
\text { Cultura Religiosa: Pessoa e Sociedade }\end{array}$ \\
\hline \multirow{7}{*}{ Rio de Janeiro } & 1 - Centro de Ensino Superior de Valença - CESVA & Psicologia da Religião \\
\hline & 2 - Universidade do Estado do Rio de Janeiro - UERJ & Imaginário Social e Religiosidade \\
\hline & $\begin{array}{l}3 \text { - Pontifícia Universidade Católica do Rio de Janeiro - } \\
\text { PUC-RIO }\end{array}$ & O Humano e o Fenômeno Religioso \\
\hline & 4 - Instituto Tecnológico e das Ciências Sociais & \\
\hline & Aplicadas e da Saúde do Centro Educ. N. Sr ${ }^{\mathrm{a}}$ & O Homem e o Fenômeno Religioso \\
\hline & Auxiliadora - ITCSAS/CENSA & \\
\hline & 5 - Faculdade Salesiana Maria Auxiliadora - FSMA & O Homem e o Fenômeno Religioso \\
\hline \multirow{4}{*}{ São Paulo } & $\begin{array}{l}1 \text { - Centro Universitário Adventista de São Paulo - } \\
\text { UNASP }\end{array}$ & Religiosidade e Competência Profissional \\
\hline & $\begin{array}{l}2 \text { - Centro Universitário Católico Salesiano Auxilium - } \\
\text { UNISALESIANO }\end{array}$ & Cultura Teológica \\
\hline & 3 - Universidade do Sagrado Coração - USC & Ética e Cultura Religiosa \\
\hline & 4 - Universidade de Sorocaba - UNISO & Cultura, Religiosidade e Mudança Social \\
\hline \multirow{6}{*}{ Paraná } & 1 - Centro Universitário Filadélfia - UNIFIL & Psicologia da Saúde e Espiritualidade \\
\hline & $\begin{array}{l}2 \text { - Faculdade de Administração, Ciências, Educação e } \\
\text { Letras - FACEL }\end{array}$ & Cultura Religiosa \\
\hline & 3 - Faculdade Sant'ana - IESSA & Ciências Religiosas \\
\hline & 4 - Universidade Federal do Paraná - UFPR & Psicologia e Religião \\
\hline & $\begin{array}{l}5 \text { - Pontifícia Universidade Católica do Paraná - } \\
\text { PUCPR }\end{array}$ & Cultura Religiosa \\
\hline & 1 - Centro Universitário La Salle - UNILASALLE & Fenômenos culturais e religiosos \\
\hline \multirow{5}{*}{$\begin{array}{l}\text { Rio Grande do } \\
\text { Sul }\end{array}$} & 2 - Universidade Católica de Pelotas - UCPEL & $\begin{array}{l}\text { Saúde e espiritualidade em diálogo: } \\
\text { desafios, limites e possibilidades }\end{array}$ \\
\hline & & Ciência e fé \\
\hline & $\begin{array}{l}3 \text { - Pontifícia Universidade Católica do Rio Grande do } \\
\text { Sul - PUCRS }\end{array}$ & Humanismo e Cultura Religiosa \\
\hline & 4 - Faculdade São Francisco de Assis - UNIFIN & Psicologia e Espiritualidade \\
\hline & 5 - Universidade Luterana do Brasil - ULBRA & Cultura Religiosa \\
\hline Santa Catarina & 1 - Universidade do Vale do Itajaí - UNIVALI & Psicologia da espiritualidade \\
\hline TOTAL & 28 & 31 \\
\hline
\end{tabular}


Das 28 instituições que apresentavam, portanto, disciplinas com nomes sugestivos, apenas 10 disponibilizam o conteúdo de suas ementas nas plataformas virtuais. Duas dessas instituições disponibilizam mais de uma disciplina referente ao assunto, ambas localizadas no estado de Minas Gerais (Universidade Federal de Minas Gerais: "Freud e a Religião" e "Psicologia e Senso Religioso" e a Pontifícia Universidade Católica de Minas Gerais: "Cultura Religiosa: Fenômeno Religioso" e "Cultura Religiosa: Pessoa e Sociedade"). A busca pelos sites totalizou, portanto, 12 ementas dentre as 31 de disciplinas disponíveis. Conforme o planejamento, foram enviados emails para os coordenadores de 18 cursos de Psicologia restantes, solicitando aos mesmos o detalhamento da disciplina, incluindo sua ementa curricular. Foram recebidas três respostas positivas, ficando a amostra final constituída por 15 ementas.

A integração dos aspectos religiosos/espirituais com a prática profissional foi encontrada em apenas 4 (quatro) descrições disciplinares, sendo elas: "Psicologia e Senso Religioso" (Universidade Federal de Minas Gerais - UFMG), "Cultura Religiosa" (Faculdade de Administração, Ciências, Educação e Letras - FACEL), "Psicologia e Religião" (Universidade Federal do Paraná - UFPR) e "Psicologia da Espiritualidade" (Universidade do Vale do Itajaí - UNIVALI).

As descrições incluíam "teorias psicológicas e sua inter-relação com o senso religioso", "conhecimento das principais religiões mundiais e as suas relações psicológicas", "áreas de intersecção entre paradigmas religiosos e psicológicos" e "espiritualidade e aconselhamento psicológico". Todas as descrições das ementas disciplinares das 4 disciplinas referem uma inter-relação entre o conhecimento teórico dos aspectos espirituais/religiosos e a prática psicológica, além da correlação com os aspectos e fenômenos psicológicos. Nas demais ementas $(n=11)$, o estudo dos aspectos religiosos/espirituais apresentou-se de maneira isolada, ou melhor, de maneira mais informativa a respeito das diferentes religiões, descrições dos fenômenos religiosos, bem como aspectos sociológicos, históricos e culturais das religiões.

\section{Discussão}

$\mathrm{O}$ acesso ao conhecimento sobre $\mathrm{E} / \mathrm{R}$, da forma como tem sido geralmente realizada, proporciona ao estudante de Psicologia, um entendimento do fenômeno religioso meramente conceitual e generalizado. A maneira de abordagem dessa temática 
tem se mostrado limitada na compreensão dos aspectos $\mathrm{E} / \mathrm{R}$, restringindo-se à descrições das diferentes confissões religiosas e suas práticas e às questões dos cuidados éticos na abordagem da $\mathrm{E} / \mathrm{R}$ do paciente. Pouca atenção é dada à aspectos de capacitação do futuro profissional para a intervenção junto aos pacientes na abordagem e integração da E/R, sendo este tema tratado como assunto secundário.

Ancona-Lopez (2005) já alertava que, salvo algumas exceções, nos currículos dos cursos de Psicologia em nosso país, dificilmente são encontrados conteúdos que abordem os aspectos da E/R. Portanto, os futuros psicólogos, tem poucas possibilidades de integrar as experiências religiosas e espirituais aos conhecimentos psicológicos. Inclusive, estes alunos não encontram espaço para discutir suas próprias experiências e poder, assim, desenvolver uma postura científica e técnica que acolha a vivência da $\mathrm{E} / \mathrm{R}$ do paciente sem necessariamente fundamentá-la na sua experiência pessoal. Isto ficou claro no levantamento efetuado pois, das 291 instituições identificadas, o tema da E/R apareceu em apenas 28 .

Sabe-se que não é função da Psicologia, mesmo quando está voltada para o estudo da experiência religiosa, posicionar-se a respeito da comprovação das verdades de fé, mas, cabe à Psicologia, a investigação sobre a forma e a razão do porquê as pessoas aderem a determinadas verdades, as quais podem representar vários tipos de personalidades. A experiência do sagrado pela pessoa não é um acontecimento estranho, mas comum a condição humana, mesmo que a ciência tenha dificuldade de integrar tais experiências em seu cabedal de conhecimentos. Trata-se de uma vivência na qual algo é sentido, pensado, interrogado, algo com que se estabelece uma relação. Neste sentido Ribeiro (2015) ressalta que

O psicólogo não tem que acreditar em Deus ou ser religioso, mas precisa aprender a convier com um Deus que mora na sua humanidade ou no cosmos e que se expressa, frequentemente nos homens [e mulheres], nos nossos clientes, por meio de gestos que incluem fé, amor, esperança e, também, muitas vezes, medo, temor e angústia (p.14).

Segundo Allport (1975), existe uma diversidade quanto ao grau de influência que a religião exerce na vida das pessoas, bem como, nas formas de maturidade relativas à maneira como cada pessoa vive sua religiosidade. O autor indica que estas diferenças se devem ao fato do desenvolvimento religioso do ser humano ser influenciado por seu temperamento e formação, estando também sujeito à interrupção durante o seu processo de crescimento religioso. Giovanetti (2004) ressalta que, para entender a experiência 
religiosa, é importante não a desvincular das formas de religiosidade presentes no contexto em que se vive. Neste mesmo sentido Pargament (1997) reforça que o uso de enfrentamento religioso só adquire sentido se essas crenças fizerem parte do sistema de valores do paciente. Valle (2005), numa perspectiva psicanalítica, afirma que compete ao psicólogo investigar quais as motivações, sentimentos, desejos, compreensões e atitudes são expressas nos comportamentos religiosos. Neste sentido, o profissional deve buscar compreender a dinâmica da experiência e do comportamento religioso, entendendo-a como uma vivência que influencia, singularmente, o seu desenvolvimento pessoal e sua vida.

Ribeiro (2015), reforça, em suas reflexões o fato da Psicologia, sobretudo a acadêmica, ter adotado uma postura como se a religião não existisse, apesar de se perceber que sua existência refletira uma necessidade básica do ser humano, para responder e explicar os acontecimentos da vida e dar-lhes sentido. Ribeiro (2015) também ressalta que

\begin{abstract}
A Psicologia tem dois caminhos para lidar com o fenômeno de Deus Primeiro, enquanto uma unidade de significados, enquanto uma realidade ontológica, um objeto de conhecimento para a consciência, como estudaria, por exemplo, o amor, enquanto unidade abstrata de sentido. Segundo, estudaria Deus enquanto vivência e experiência humana: Deus, aqui e agora, como algo inerente à cotidianidade do ser humano, amado, adorado por uns, odiado, negado por outros (Ribeiro, 2015, p.16).
\end{abstract}

É, portanto, preocupante que, neste universo estudado, apenas foram identificadas quatro disciplinas que indicam estarem realmente voltadas à instrumentação do profissional psicólogo para integração dos aspectos da $\mathrm{E} / \mathrm{R}$ do paciente, bem como a possibilidade de identificar seus próprios valores e vivências. A questão da E/R do próprio estudante tem sido motivo de diversos estudos os quais, de modo geral, apontam que os alunos percebem o ambiente acadêmico como hostil para a discussão desta temática (Pereira \& Holanda, 2016), que há um declínio da espiritualidade dos alunos durante sua formação (Cavalheiro \& Falcke, 2014), que o estudante vivencia um constante conflito ao longo do curso, revelando frequentemente sentimentos de despreparo e insegurança para lidar com as questões religiosas de seus futuros pacientes, pois percebem que as teorias psicológicas aprendidas tendem a "patologizar" as experiências E/R (Freitas, 2015; Freitas \& Abreu e Silva, 2003) e que há uma falta de condições na graduação para que o aluno desenvolva uma postura crítica quanto à própria religiosidade $\mathrm{e}$ 
espiritualidade, condição necessária para o não preconceito e a verdadeira aceitação do outro (Freitas \& Piasson, 2016, p.109; Goldelman, 2013).

Para Angerami-Camon (2004), é necessário que o psicoterapeuta esteja aberto para poder acolher o conteúdo trazido pelo paciente no que se refere aos seus valores religiosos e espirituais, mantendo uma atitude de aceitação, sem julgamentos e preconceitos. Para isto é de suma importância que o profissional conheça seus próprios valores a fim de não se perder em conflitos frente aos valores do paciente. Nesta mesma linha, Ancona-Lopes (2005) ressalta que a dificuldade do psicólogo em lidar com a religiosidade dos seus pacientes reside na dificuldade de o mesmo lidar com seus próprios preconceitos. A autora aponta ainda a grande importância do psicoterapeuta tomar distância de suas próprias representações religiosas ao lidar com este fenômeno no contexto psicoterapêutico e indica a necessidade de ele suspender suas próprias representações para não projetá-las no paciente.

Considerando-se os atuais estudos já acima citados, que comprovam os benefícios da integração dos aspectos E/R para paciente, entende-se que, provavelmente, aspectos pessoais, éticos e de formação podem estar envolvidos na dificuldade dos profissionais psicólogos abordarem os fenômenos da manifestação dos aspectos E/R. Isto demonstra a importância de uma abordagem mais estruturada, visando instrumentar este profissional para uma formação mais humanizada, integral e realista.

\section{Questões de Formação e Proposta de Disciplina}

Como visto neste estudo, temas ligados à religião ainda estão ausentes no meio acadêmico. Este dado também é corroborado por Costa, Nogueira \& Freire (2010) em outro estudo das grades curriculares de Psicologia no Brasil, na qual o autor encontrou que $84 \%$ dos cursos não referem temas de espiritualidade em seus currículos. Os cursos de Psicologia não estimulam o acesso do estudante a trabalhos desenvolvidos neste campo, o que poderia facilitar um olhar psicológico não redutor aos fenômenos religiosos e espirituais. Geralmente, os cursos apresentam ao estudante apenas as posições da Psicologia que excluem as experiências religiosas e espirituais do âmbito de seus estudos ou as focalizam como psicopatológicas.

Neste sentido, uma adequada instrumentalização deveria dar conta de preparar estes profissionais para pelo menos três posições: 
a) Se as crenças do profissional coincidem com as do paciente: é importante o psicólogo estar treinado para não confundir seu papel profissional e passar a escolher suas intervenções baseado nos seus credos religiosos, perdendo de vista a dinâmica psicológica do paciente que inclui o modo como este paciente se utiliza das suas próprias crenças.

b) Se as crenças do profissional são contrárias as crenças dos pacientes: é importante o psicólogo estar treinado para não entrar em conflito com seu paciente, o que pode inclusive se manifestar pela negligência por parte do profissional na abordagem aos aspectos $\mathrm{E} / \mathrm{R}$ deste paciente, por causar desconforto no profissional.

c) Se o profissional preferir não ter nenhuma crença E/R: a inexistência de crenças pessoais por parte do profissional não implica que este não possa avaliar e acolher as crenças do paciente e como estas influenciam nos processos de saúde e doença. Esta perspectiva também é reconhecida por Propst et al (1992).

Apresenta-se a seguir uma proposta possível de disciplina a nível da graduação, que possa aprimorar o estudo, a pesquisa e discussão a respeito da temática da $E / R$, bem como o manejo a respeito deste tema (Quadro 1). A mesma será apresentada no modelo geralmente exigido para contemplar as grades curriculares, de modo a facilitar seu uso e adaptação.

\section{Quadro 1.}

Proposta de disciplina.

\section{Religiosidade/espiritualidade na prática da psicologia da saúde/hospitalar}

Ementa: Influência da dimensão espiritual e religiosa no comportamento do ser humano: nas suas diferentes fases de desenvolvimento e amadurecimento; no seu relacionamento com os membros da comunidade de fé; no processo da doença; na adaptação às limitações físicas; na aderência aos tratamentos; no controle das doenças crônicas; na aceitação do sofrimento inevitável imposto pela perda de capacidades e da própria vida; nos cuidados paliativos; teoria do apego à Deus; nas questões de conflitos espirituais. Respeito à espiritualidade do paciente em benefício do tratamento e da relação profissional-paciente.

Público: Alunos a partir do sexto período do curso de psicologia, pois são necessários conhecimentos básicos sobre psicopatologia, desenvolvimento e fundamentos de personalidade. Também podem participar da disciplina alunos dos cursos de enfermagem, fisioterapia, medicina e nutrição, por serem profissionais que lidam diretamente com pacientes em situações graves em hospital geral. Estes alunos de outros cursos devem também estar cursando os últimos períodos supondo-se assim um melhor conhecimento teórico e prático da abordagem ao paciente.

Objetivo: Ao finalizar o curso o estudante deverá perceber a importância da Espiritualidade/Religiosidade como fator de influência no acompanhamento do paciente no processo saúde-doença, conhecer escalas de avaliação de $\mathrm{E} / \mathrm{R}$, utilizar adequadamente formas de investigação e intervenção dos aspectos $\mathrm{E} / \mathrm{R}$ dos pacientes e entender sua participação como instrumento de humanização no atendimento em equipes multidisciplinares. 
Continuação Quadro 1.

\section{Objetivos específicos:}

- Capacitar profissionais da área da saúde para compreender as relações entre religiosidade/espiritualidade $(\mathrm{R} / \mathrm{E})$, diferenciando entre experiências positivas e negativas;

- Oferecer subsídios histórico-epistemológicos para a promoção do debate entre ciência, psicologia e E/R;

- Instrumentalizar os profissionais para a identificação e diferenciação entre experiências positivas e negativas que envolvem $\mathrm{E} / \mathrm{R}$ e saúde;

- Instrumentalizar o profissional na integração de temas de E/R na prática do cuidado ao paciente e sua família nos contesto dos cuidados paliativos;

- Promover recursos técnicos para possíveis intervenções clínicas relacionadas a E/R, tais como o uso de escalas e instrumentos de avaliação do coping religioso espiritual, conflitos espirituais, apego a Deus, e outros instrumentos de avaliação da $\mathrm{E} / \mathrm{R}$ do paciente.

- Ressaltar a importância da prática interdisciplinar, principalmente no que ser refere aos cuidados paliativos.

\section{Programa:}

1. Aspectos conceituais (ciências da religião, psicologia da religião, coping religioso, humanização, bioética, teoria do apego à Deus).

2. Fundamentos Epistemológicos e históricos do estudo E/R visão da religiosidade para alguns dos principais teóricos da psicologia).

3. O lugar da pessoa e da doença nas diferentes religiões.

4. A influência dos aspectos $\mathrm{E} / \mathrm{R}$ nos processos de saúde/doença (cardíacos, câncer, pressão arterial, doenças crônicas, pré e pós-operatórios, cuidados paliativos, etc).

5. Práticas $\mathrm{E} / \mathrm{R}$ e sua interface com a neurociência.

6. Escalas de avaliação da $\mathrm{E} / \mathrm{R}$ e fundamentos para o diagnóstico diferencial.

7. O exercício profissional e a abordagem dos aspectos $\mathrm{E} / \mathrm{R}$ (casos clínicos).

8. Questões de ética.

Fonte: autoria própria.

\section{Considerações finais}

A E/R é uma dimensão estruturante na subjetividade humana. Neste sentido, ao deparar-se com situações limite, o indivíduo certamente usará essa dimensão como fonte para a construção de sentido da experiência de sofrimento pelo qual está passando. Assim, ao fazer uso de estratégias de coping de caráter E/R para o enfrentamento de tais situações de sofrimento, essas estratégias tanto podem contribuir positivamente no enfrentamento do sofrimento, quanto podem se constituir como fonte de maior sofrimento. Indivíduos em tais situações podem se defrontar com conflitos espirituais.

Os dados empíricos demonstram a necessidade urgente da Psicologia reconhecer esta realidade e rever sua posição geralmente silenciosa ou, que muitas vezes, até desqualificam a temática. Não cabe mais manter posições preconceituosas que, na quase totalidade dos casos, estão fundamentadas em um não saber, em falta de conhecimento e aprofundamento sobre o tema.

É imperativo que se reveja a postura dos centros de formação, incluindo-se tanto a presença do tema na grade curricular, como a postura dos docentes em outras disciplinas, para que estes possam transformar sua postura geralmente defensiva, em uma 
postura acolhedora e investigativa, a luz das novas pesquisas na área da E/R. É necessário, inclusive, criar condições propícias para que os estudantes de Psicologia possam compartilhar suas crenças e experiências pessoais, sem medo de serem ironizados e remetendo-os futuramente ao mau uso destas crenças, pois as dificuldades dele compreender a integração entre suas teorias, sua própria religiosidade e os aspectos $\mathrm{E} / \mathrm{R}$ apresentados pelos seus pacientes decorre, principalmente, da falta de estudos, reflexões e interesse da Psicologia sobre o tema.

Portanto, é necessário compreender que incluir/integrar a $\mathrm{E} / \mathrm{R}$ dos pacientes nos atendimentos, principalmente na área da psicologia da saúde hospitalar, não depende das crenças dos profissionais psicólogos. Como destaca Pargament (2007) as escolhas pessoais a respeito da $\mathrm{E} / \mathrm{R}$ não se constituem, necessariamente, como recursos eficazes e suficientes para o psicoterapeuta conduzir uma intervenção espiritualmente integrada, pois a compreensão da E/R exige uma preparação formal.

Portanto, percebe-se que há uma necessidade urgente de uma ampliação na formação acadêmica dos psicólogos, para abarcar os avanços já alcançados pela Psicologia como ciência e profissão. Mais do que criticar, pretende-se contribuir com propostas e práticas concretas, que efetivamente ampliem a reflexão e o manejo desta importante dimensão do ser humano.

\section{Referências}

Allport, G.W. (1975). Desenvolvimento da personalidade: considerações básicas. São Paulo: EPU.

Ancona-Lopez, M. (2005). Espiritualidade e os psicólogos. In M.M. Amatuzzi (Org.), Psicologia e espiritualidade (pp. 147-159). São Paulo: Paulus.

Angerami- Camon, V.A. (2004). De espiritualidade, de ateísmo e de psicoterapia. In V.A. Angerami-Camon (Org.), Espiritualidade e prática clínica (pp. 215-262). São Paulo: Thomson.

Ávila, A. (2007). Para conhecer a psicologia da religião. São Paulo: Edições Loyola.

Beit-Hallahmi, B. (1989). Prolegomena to the psychological study of religion. London: Bucknell University press.

Byrnes, J.F. (1984). The Psychology or Religion. New York: Collier Macmillan Publishers.

Cavalheiro, C. M., \& Falcke, D. (2014). Espiritualidade na formação acadêmica em psicologia no Rio Grande do Sul. Revista Estudos de Psicologia, 31(1), 35-44. 
Costa, W., Nogueira, C., \& Freire, T. (2010). The lack of teaching/study of religiosity/spirituality in psychology degree courses in Brazil: The need for reflection. Journal of Religion and Health, 49, 322-332.

Elias, A.C., \& Giglio, J.S. (2001). A questão da espiritualidade na realidade hospitalar: o psicólogo e a dimensão espiritual do paciente. Estudos de Psicologia, 18(3), 23-32.

Esperandio, M.R.G. (2014). Teologia e a pesquisa sobre espiritualidade e saúde: um estudo piloto entre profissionais da saúde e pastoralistas. Revista Horizonte, 12(35), 805-832.

Freitas, M. H., \& Piasson, D. L. (2016) Religião, religiosidade e espiritualidade: repercussão na mídia e formação profissional em psicologia. Esferas, 5 (8), 103-112.

Freitas, M.H. (2015). Psicologia religiosa, psicologia da religião ou psicologia e religião? [Resumo]. In Anais do X Seminário de Psicologia e Senso Religioso. Curitiba: Pontifícia Universidade Católica do Paraná.

Freitas, M.H., \& Abreu e Silva, N.N. (2003). Crença religiosa e personalidade em estudantes de Psicologia: um estudo por meio do questionário Pratt e do Método de Rorschach. Boletim da Academia Paulista de Psicologia, 23(2), 19-24.

Geronasso, M.C., \& Coelho, D. (2012). A influência da religiosidade/espiritualidade na qualidade de vida das pessoas com câncer. Rev. Saúde Meio Ambiente, 1(1).

Gil, A.C. (2002). Como elaborar projetos de pesquisa. São Paulo: Atlas.

Giovanetti, J.P. (2004). A representação da religião na pós-modernidade. In G.J. Paiva, \& W. Zangari (Org.). A representação na religião: perspectivas psicológicas. São Paulo: Loyola.

Gobatto, C.A., \& Araújo, T.C. (2010). Coping religioso-espiritual: reflexões e perspectivas para a atuação do psicólogo em oncologia. Revista SBPH, 13(1), 52-63.

Goldelman, T.C. (2013). A religiosidade e a espiritualidade dos alunos no curso de formação de psicologia. Dissertação de mestrado não publicada, Pontifícia Universidade Católica de São Paulo, São Paulo, SP, Brasil.

Hefti, R. (2011). Integrating religion and spirituality into mental health care, psychiatry and psychotherapy. Religions, 2(1), 611-627.

Junior, F.G. (2011). Psicologia clínica e espiritualidade/religiosidade: interlocução relevante para a prática clínica contemporânea. Psicologia Rev., 20(1), 29-41.

Koenig, H.G. (2012). Medicina, religião e saúde: o encontro da ciência e da espiritualidade. Porto Alegre: L\&PM.

Paiva, G.J. (2005). Psicologia da religião, psicologia da espiritualidade: oscilações conceituais de uma (?) disciplina. In M.M. Amatuzzi (Org). Psicologia e espiritualidade. São Paulo: Paulus.

Pargament, K.I. (1997). The psychology of religion and coping: theory, research and practice. New York: Guilford Press.

Pargament, K.I. (2007). Uma orientação para a psicoterapia espiritualmente integrada. In K.I. Pargament. Psicoterapia espiritualmente integrada: compreender a abordagem do sagrado. New York: Guiford Press. 
Pereira, K.C. (2007). As vozes do silenciado: estudos nas fronteiras da antropologia, filosofia e psicologia. Brasília: Universa.

Pereira, K.C., \& Holanda, A.F. (2016). Espiritualidade e religiosidade para estudantes de psicologia: ambivalências e expressões do vivido. Revista Pistis Praxis, 8(2), 385-413.

Peres, J.F. (2004). Psicoterapia e espiritualidade: convergência possível e necessária. In E.F. Teixeira, M.G. Muller, \& J.D. Silva (Org.). Espiritualidade e qualidade de vida. Porto Alegre: EDIPUCRS.

Peres, J.F., Simão, M.J.P, \& Nasello, A.G. (2007). Espiritualidade, religiosidade e psicoterapia. Revista Psiquiatria clínica, 34(1), 136-145.

Propst, L.R., Ostrom, R., Watkins, P., Dean. T. \& Mashburn, D. (1992) Comparative efficacy of religious and nonreligious cognitive-behavior therapy for the treatment of clinical depression in religious individuals. Journal of Consulting and Clinical Psychology, 60, 94-103.

Ribeiro, J.P. (2015). Religião e psicologia. In A. Holanda (Org.). Psicologia, religiosidade e fenomenologia. Campinas: Alinea.

Teixeira, J.J, \& Lefèvre, F. (2003). Humanização nos cuidados de saúde e a importância da espiritualidade: o discurso do sujeito coletivo-psicólogo. O mundo da saúde, $27(3)$.

Valle, J.E. (2005). Religião e espiritualidade; um olhar psicológico. In M.M. Amatuzzi (Org.), Psicologia e espiritualidade (pp. 83-107). São Paulo: Paulus. 